\title{
029 PUBLIC PRIVATE PARTNERSHIP IN THE MANAGEMENT OF HEALTH SERVICES IN PAKISTAN
}

Faheem Ahmed Khanzada. Global Health, Partnership in Global Health, Karachi, Pakistan

10.1136/bmjopen-2015-forum2015abstracts.29

Background The government of Pakistan is committed to achieving the post millennium development goals in partnership with the World Health Organization, International monetary funds and the World Bank. To facilitate the challenges of globalization and achieving a prosperous Pakistan in the 21st century partnership stakeholders secretariat practicing collaboration of the public health subsystems together public and private medical universitities hospital to raise the health status of society.

Objectives To describe the aspiration of public private partnership stakeholders in practicing the utility of primary health care services in Pakistan.

Methods The operational policies and the practices of collaboration in the utility of primary health care services in the towns, Pakistan, from 2006 to 2013 was analyzed by using documents, interviews with key informants and participant observation. Universality, redistribution, policy, practice, attitude, belief, oral poliomylitis vaccine, integration and plurality, quality, establishment etc in health services were judge as the analytical categories took by the office of administration in 2001, to conform the national health policy continue until the present date.

Result The practices of the collaboration in health management in Pakistan, related to true changes are the political, personal gain, establishment, belief, poliomylitis etc. Socialization is variable to make headway for the town to assume the pessimistic management of the entire health system, so that all health subsystems coexisted.

Conclusion The health management in the municipality towns was unsustainable variable, mainly because it was not the stakeholder's priority to spending on primary health care and was not a trademark of the de facto administration.

\section{BIBLIOGRAPHY}

1 F Ahmed, N Nisar. Public-private partnership scenario in the health care system of Pakistan. Eastern Mediterranean Health Journal, EMHJ • 2010;16:8 •.

2 Todor Tagarev, Valari Ratchev, It 4 Sec Reports, Civil-Military Interaction in the EU's Comprehensive Approach, Institute of Information and Communication Technologies, Center for Security and Defense Management, Sofia, December 2011. 
3 Burch A, Higgins BR, Jennings CA, Johonson, et al., Toward a Comprehensive Approach: Integrating Civilian and Military Concept of Strategy, Forum Paper no.15. Room: NATO Defence College, 2011.

4 Army establish field hospital in drought-hit Tharparkar, The Frontier Post, Posted on 2014-03-09 09:04:33, http://thefrontierpost.com/article/80940/Army-establish-fieldhospital-in-drought-hit-Tharparkar/ (accessed 09 Mar 2014)

5 Siegmann KA, Shaheen N, Shah S. Collaboration between state and non-state providers of basic services in Pakistan. Islamabad, Pakistan, Sustainable Development Policy Institute, 2006.

6 Georgiev V, Policies, Outlooks for the MOD activities on the field of Public Private Partnerships, Military Journal 2007;114:120-30.

7 Shalamanov V, Tagarev T, Anglevo A, The Officer in the Reserve: A natural Bridgebetween the Armed Forces and the Civil Society. Sofia: Union of the Officers in the Reserve Atlantic 